\title{
CARACTERÍSTICAS E PATOGENICIDADE DA SALMONELLA ENTERICA: UMA \\ REVISÃO DE LITERATURA
}

\section{CHARACTERISTICS AND PATHOGENICITY OF SALMONELLA ENTERICA: A LITERATURE REVIEW}

\author{
Danrley Oliveira Carneiro', Misael Silva Ferreira Costa ${ }^{2}$
}

\begin{abstract}
1 - Graduando em Biomedicina pela Faculdade Nobre de Feira de Santana - FAN - Feira de Santana, Bahia, Brasil. 2 - Doutor em Microbiologia pela Universidade Federal de Pernambuco - UFPE, docente da Unidade de Ensino Superior de Feira de Santana - UNEF - Feira de Santana, Bahia, Brasil.

Autor para correspondência: Danrley.Oliveira@gmail.com
\end{abstract}

\section{RESUMO:}

Introdução: A Salmonella enterica é a principal causa de infecções gastrointestinais em humanos. É um bacilo gram-negativo da família das Enterobacteriaceae não fermentadora de lactose. Sua transmissão ocorre através das fezes contaminadas e do consumo de água e alimentos como salsichas, ovos, frango, carnes bovinas, suínas, verduras e hortaliças contaminados. Metodologia: Foi realizada uma revisão literária, baseando-se em publicações entre os anos de 2004 a 2019. Resultados: Foram encontrados 142 artigos relacionados à temática abordada, 7 livros e 4 Procedimentos Operacionais Padrões POP, sendo selecionados 17 artigos, 3 livros e 1 POP. Conclusão: Pôde-se concluir que a Salmonella enterica apresenta complexas estratégias de invasão do epitélio intestinal, sendo capaz de iniciar respostas inflamatórias levando a gastroenterites; os sorotipos Enteritidis e Typhimurium parecem ser particularmente importantes para este processo inflamatório intestinal.

PALAVRAS-CHAVE: Salmonella, gastroenterites, inVa, salmonelose.

\section{ABSTRACT:}

Introduction: Salmonella enterica is the main cause of gastrointestinal infections in humans. It is a gram-negative bacillus from Enterobacteriaceae Family non-lactose fermenting. Its transmission occurs through contaminated feces and the consumption of water and foods such as sausages, eggs, chicken, beef, pork, and vegetables contaminated. Methodology: A literary review was carried out, based on publications between the years 2004 to 2019 . Results: 142 articles were found related to the topic addressed, 7 books and 4 Standard Operating Procedures, being selected 17 articles, 3 books and 1 Standard Operating Procedures. Conclusion: It was concluded that Salmonella enterica presents complex strategies for invasion of the intestinal epithelium, being able to initiate inflammatory responses leading to gastroenteritis; serotypes Enteritidis and Typhimurium appear to be particularly important for this intestinal inflammatory process.

KEY WORDS: Salmonella, gastroenteritis, inVa, salmonellosis.

\section{INTRODUÇÃO}

A Salmonella enterica é uma espécie bacteriana em forma de bacilo, gramnegativo, medindo de 1 a $2 \mu \mathrm{m}$. Fazem parte da família das Enterobacteriaceae que está 
relacionada com patologias de origem alimentar. A grande maioria dos sorotipos de Salmonella enterica são moveis e flageladas, sendo as únicas exceções os sorotipos Gallinarum e Pullorum (FORSYTHE, 2013). É uma bactéria anaeróbica facultativa fermentadora de glicose, que normalmente não consegue fermentar lactose e sacarose, no entanto algumas cepas podem se tornar fermentadoras de lactose mediante a transferência de plasmídeo (LEVINSON, 2011).

O habitat natural da Salmonella enterica é o trato intestinal (humano e animal), por tanto sua transmissão para o meio ambiente se dá através da liberação de fezes contaminadas. O consumo de alimentos como salsichas, ovos e frango que não dispõe de tratamento higiênico adequado, podem causar infecção em humanos. Esta bactéria pode estar presente também na água, solo, carnes bovinas, suínas, verduras e hortaliças contaminadas com fezes. (SHINOHARA et al., 2008; FERREIRA et al., 2013).

A sintomatologia aguda da infeção por Salmonella (não tifoide) inclui: dor abdominal, diarreias (em algumas situações com presença de sangue), calafrios, desidratação, exaustão, febre, cefaleia e vômitos; podendo evoluir para quadros de artrite reativa e Síndrome de Reiter, caso a infeção se torne crônica (ENGELKIRK; DUBENENGELKIRK, 2015).

Para identificar os tipos e subtipos desta bactéria, diversos testes estão disponíveis no mercado que vão desde métodos automatizados, como o sistema Vitek 2, a métodos mais complexos e de maior custo como a Reação em Cadeia da Polimerase - PCR, que possibilita a identificação e ampliação de genes de virulência específicos da bactéria (VALONES et al, 2009).

O presente artigo tem como objetivo apresentar as características e particularidades da Salmonella enterica, seus fatores de virulência, bem como os meios de isolamento e os atuais métodos diagnósticos das Salmoneloses.

\section{METODOLOGIA}

Foi realizada uma revisão sistemática utilizando as bases de dados eletrônicas PubMed, Lilacs, SciELO, BIREME e BVS utilizando-se de palavras-chave os termos: Salmonella, Salmonelose, InVa, e Patologias de Origem Alimentar. Os termos encontrados foram aplicados individualmente para refinar e testar a sensibilidade da pesquisa. $O$ termo "Salmonelose" e "Patologias de Origem Alimentar" também foram buscados no idioma inglês: "Salmonellosis" e "Foodborne Pathologies", respectivamente, para buscas no 
PubMed. Foram incluídos artigos publicados entre os anos de 2004 a 2019, nos idiomas Inglês e Português. Também foram incluídos livros e Procedimentos Operacionais Padrões para melhor definição das técnicas de diagnostico.

Foram encontrados 142 artigos relacionados à temática abordada, 7 livros e 4 Procedimentos Operacionais Padrões - POP, sendo selecionados 17 artigos, 3 livros e 1 POP. Os critérios de inclusão foram: artigos publicados entre 2004 e 2019 que abordassem o tema de forma clara; Procedimentos dos sistemas utilizados para diagnóstico e caracterização das Salmonella; livros que abordassem informações de forma objetiva e concisa. Os critérios de não inclusão foram: artigos publicados fora do período estabelecido; artigos que já tratassem do mesmo conteúdo dos artigos mais recentes e já selecionados; Procedimentos repetitivos; Livros que já dispunham de informações coletadas em edições mais atuais.

\section{RESULTADOS E DISCUSSÃO}

\subsection{Fatores de Virulência e Fisiopatologia da Infecção por S. Enterica}

Para que a infecção ocorra, é necessário que o indivíduo sadio ingira aproximadamente 105 bactérias em alimentos ou água contaminados com fezes. As virulências da Salmonella se encontram, em geral, nas Ilhas de Patogenicidade de Salmonella (SPI), que induzem a formação de sistemas capazes de injetar produtos da transcrição bacteriana no interior da célula hospedeira alterando seu funcionamento fisiológico e bioquímico (COBURN; A GRASSL; FINLAY, 2006). O gene invA possui um papel importante na invasão das células epiteliais do intestino e dos macrófagos (MOURA et al., 2014).

A bactéria tem a capacidade de invadir os enterócitos induzindo a formação de pseudópodos para que tais células as fagocitem (figura 1), mesmo que estes não sejam fagócitos naturais. Uma vez fagocitadas, se hospedam no interior celular causando uma alteração morfológica temporária, criando um vacúolo onde se alojam para sobreviver. (SHINOHARA et al., 2008) A infecção leva a inflamação, que acarreta consequentemente em diarreia, às vezes com presença de sangue. A liberação de prostaglandinas pela resposta imunológica estimula a Adenil ciclase, enzima que hidrolisa ATP, levando ao aumento de secreção de água e eletrólitos, provocando diarreia aquosa, dor abdominal, desidratação e deficiência de eletrólitos. Além disso, a liberação de pirógenos pelas células 
de defesa induzem a febre (FERREIRA et al., 2013).

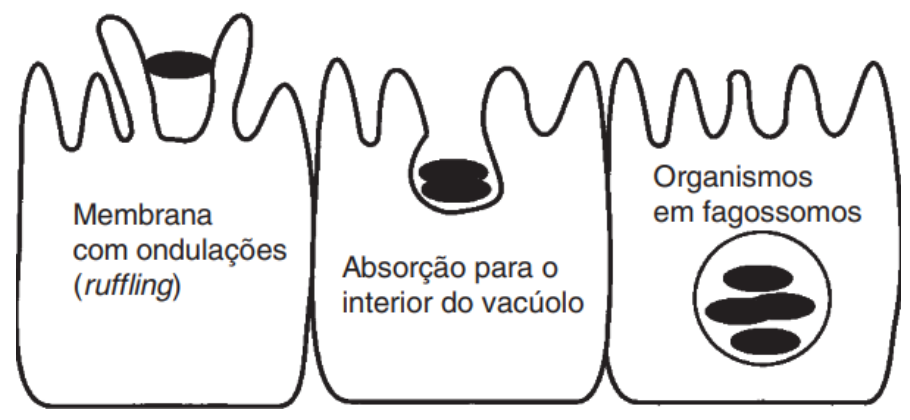

Figura 1: Invasão da parede do intestino por Salmonella (FORSYTHE, 2013).

Uma vez no interior do organismo, a bactéria poderá ser fagocitada pelas células de defesa do sistema imunológico. Dentro do macrófago, a Salmonella apresenta um mecanismo de sobrevivência similar ao utilizado nas células do epitélio intestinal, criando um vacúolo que persiste por horas ou até mesmo dias. Em indivíduos imunodeprimidos, a bactéria pode se espalhar para outros locais do corpo (DEKKER; FRANK, 2015).

Um estudo publicado na Cell Mol Life Sci, em 2011, demonstrou que o processo infeccioso por Salmonella spp é mais complexo do que parece. A bactéria é capaz de produzir mais de 400 proteínas que causam reações inflamatórias, todas codificadas a partir da SPI, mesmo que não estejam alojadas no interior da célula intestinal, sendo assim, a bactéria tem a capacidade de provocar gastroenterite mesmo no ambiente extracelular (SRIKANTH et al., 2011).

A infecção por Salmonella enterica pode provocar diversas doenças, a depender de seu sorotipo, como mostra a tabela 1. (FORSYTHE, 2013).

TABELA 1: Resumo das principais doenças causadas por Salmonella entérica

\begin{tabular}{ccc}
\hline Sorotipo & Patologia & Referência \\
\hline Enteritidis & Gastroenterites & (HASELBECK et al, 2017) \\
Typhimurium & Gastroenterites & (HASELBECK et al, 2017) \\
Typhi & Febre Tifoide & (PANÒ, 2016) \\
Paratyphi & Febre Tifoide & (JOHNSO; MYLONA; FRANKEL. 2018) \\
Paratyphi & Febre Paratifoide & (GIBANI; BRITTO; POLLARD, 2018) \\
\hline
\end{tabular}




\subsection{Características bioquímicas e meios de isolamento}

A Salmonella entérica geralmente não é fermentadora de lactose. Esta é uma caraterística importante que permite uma pré-identificação laboratorial da bactéria em isolamentos de cultura por meios diferenciais e seletivos. No Ágar MacConkey, por exemplo, as bactérias não fermentadoras de lactose metabolizam peptona presente no meio e geram amônia, alcalinizando o ambiente, tornando-o amarelo por conta do indicador de $\mathrm{pH}$. A Salmonella apresenta colônias transparentes neste meio de cultura (BRASIL, 2004).

Os açúcares que podem ser fermentados pela salmonela são: arabinose, maltose, manitol, manose, ramnose, sorbitol, trealose, xilose e dulcitol. (BRASIL, 2011). Ao fermentar a glicose, esta bactéria gera gás e ácido. É também capaz de gerar sulfeto de hidrogênio (H2S), sendo esta característica utilizada para testes laboratoriais de identificação. Além disso, é capaz de descarboxilar aminoácidos e reduzir nitrato a nitrito (LEVINSON, 2011).

Entre os meios utilizados para isolamento de Salmonella estão: Ágar EMB, Salmonella-Shigella (SS), CLED, Hektoen, XLD, Rambach, Sulfito Bismuto, Verde Brilhante, Lisina Ferro, e MLCB, além dos caldos Selenio e Tetrationato. Para transporte de amostras contaminadas é remendado o meio Stuart. Grosso modo, tais meios funcionam diferenciando as bactérias quanto a suas características metabólicas (como detecção da fermentação ou não fermentação da lactose e produção de H2S) que refletem em suas aparências de colônias (BRASIL, 2011; BRASIL, 2004; FORSYTHE, 2013).

De forma automatizada, a Salmonella spp pode ser identificada através do sistema VITEK. Este sistema utiliza cartas de plástico para incubação e inoculação do microrganismo, realizando testes bioquímicos para sua identificação. O sistema realiza também, testes de sensibilidade a antibióticos através de micro poços contendo concentrações de diversos antibióticos para avaliar a concentração mínima de inibição do crescimento bacteriano. A incubação e leitura do cartão são controladas pelo sistema, sem a necessidade de intervenção humana (MINAS GERAIS, 2019).

A Salmonella spp pode também ser identificada e caracterizada através da técnica de Reação em Cadeia da Polimerase - PCR. Os primers: (5'GTGAAATTATCGCCACGTTC GGGCAA3') e (5'TCATCGCACACGTCAAAGGACC3') são utilizados para detecção do gene inVa, considerado o padrão ouro para identificação da bactéria (KADRY et al., 2019).

\section{CONCLUSÃO}


A infecção por Salmonella enterica em humanos é complexa. A bactéria apresenta estratégias de invasão dos enterócitos com uma gama de proteínas capazes de iniciar uma resposta inflamatória e consequentemente levando a gastroenterites; os sorotipos Enteritidis e Typhimurium parecem ser particularmente importantes para este processo inflamatório intestinal. Ao observar os meios de transmissão da bactéria, é notável que tal infecção esteja intimamente relacionada com condições de falta de higiene (dos alimentos e/ou dos manipuladores) e com condições socioeconômicas e falta de saneamento básico.

\section{REFERÊNCIAS}

BRASIL. Ministério da Saúde. Secretaria de Vigilância em Saúde. Departamento de Apoio à Gestão de Vigilância em Saúde. Manual Técnico de Diagnóstico Laboratorial da Salmonella spp. Brasília: Ministério da Saúde, 2011.

BRASIL. Ministério da Saúde. Secretaria de Vigilância em Saúde. Descrição dos Meios de Cultura Empregados nos Exames Microbiológicos. Brasília: Ministério da Saúde, 2004.

CHIU, C.-h.; SU, L.-h.; CHU, C.. Salmonella enterica Serotype Choleraesuis: Epidemiology, Pathogenesis, Clinical Disease, and Treatment. Clinical Microbiology Reviews, [s.I.], v. 17, n. 2, p.311-322, 1 abr. 2004.

COBURN, Bryan; A GRASSL, Guntram; FINLAY, B B. Salmonella, the host and disease: a brief review. Immunology And Cell Biology, [s.I.], v. 85, n. 2, p.112-118, 5 dez. 2006.

DEKKER, John P.; FRANK, Karen M.. Salmonella, Shigella, and Yersinia. Clinics In Laboratory Medicine, [s.I.], v. 35, n. 2, p.225-246, jun. 2015.

ENGELKIRK, Paul G.; DUBEN-ENGELKIRK, Janet. Infecções Bacterianas. In: ENGELKIRK, Paul G.; DUBEN-ENGELKIRK, Janet. Burton Microbiologia para as ciências da saúde. 9. ed. Rio de Janeiro: Grn Guanabara Koogan, 2015. Cap. 19. p. 332-357.

FERREIRA, Lídia Lopes et al. Salmonelose em sanidade avícola e saúde pública. Revista Eletrônica Nutritime, [s.I.], v. 10, n. 5, p.2716-2751, set. 2013. 
FORSYTHE, Stephen J.. Métodos de detecção e caracterização: Salmonella spp.. In: FORSYTHE, Stephen J.. Microbiologia da Segurança dos Alimentos. 2. ed. Porto Alegre: Artmed, 2013. Cap. 5. p. 295-346.

FORSYTHE, Stephen J.. Patógenos de origem alimentar: Salmonella spp.. In: FORSYTHE, Stephen J.. Microbiologia da Segurança dos Alimentos. 2. ed. Porto Alegre: Artmed, 2013. Cap. 4. p. 193- 294.

GIBANI, Malick M.; BRITTO, Carl; POLLARD, Andrew J.. Typhoid and paratyphoid fever. Current Opinion In Infectious Diseases, [s.I.], v. 31, n. 5, p.440-448, out. 2018.

HASELBECK, Andrea H. et al. Current perspectives on invasive nontyphoidal Salmonella disease. Current Opinion In Infectious Diseases, [s.I.], v. 30, n. 5, p.498-503, out. 2017.

JOHNSON, Rebecca; MYLONA, Elli; FRANKEL, Gad. TyphoidalSalmonella: Distinctive virulence factors and pathogenesis. Cellular Microbiology, [s.I.], v. 20, n. 9, p.283-294, 9 ago. 2018.

KADRY, Mona et al. Molecular diversity of the invA gene obtained from human and egg samples. July-2019, [s.I.], v. 12, n. 7, p.1033-1038, jul. 2019.

LEVINSON, Warren. Bacilos Gram-Negativos Relacionados ao Trato Intestinal: SALMONELLA. In: LEVINSON, Warren. Microbiologia médica e imunologia. 10. ed. Porto Alegre: Amgh, 2011. Cap. 18. p. 140-157.

MINAS GERAIS. Instituto de Previdência dos Servidores do Estado de Minas Gerais - IPSEMG.

PROCEDIMENTO OPERACIONAL PADRÃO: UTILIZAR O VITEK 2. Disponível em <http://www.ipsemg.mg.gov.br/ipsemg/ecp/files.do?evento=download\&urlArqPIc=pop_ lab_mic_-_032_2019.pdf> Acessado em 11 de Setembro de 2019.

MOURA, M.s. et al. Genes de virulência e diversidade genética em Salmonella spp. isoladas de amostras de origem suína. Arquivo Brasileiro de Medicina Veterinária e Zootecnia, [s.I.], 
v. 66, n. 5 , p.1367-1375, out. 2014.

PANÒ, Stefania. Mechanisms of Salmonella Typhi Host Restriction. Biophysics Of Infection, [s.I.], p.283-294, 2016.

SHINOHARA, Neide Kazue Sakugawa et al. Salmonella spp., importante agente patogênico veiculado em alimentos. Ciência \& Saúde Coletiva, [s.I.], v. 13, n. 5, p.1675-1683, out. 2008.

SHINOHARA, Neide Kazue Sakugawa et al. Salmonella spp., importante agente patogênico veiculado em alimentos. Ciência \& Saúde Coletiva, [s.I.], v. 13, n. 5, p.1675-1683, out. 2008.

SRIKANTH, C. V. et al. Salmonella effector proteins and host-cell responses. Cellular And Molecular Life Sciences, [s.I.], v. 68, n. 22, p.3687-3697, 9 out. 2011

VALONES, Marcela Agne Alves et al. PRINCIPLES AND APPLICATIONS OF POLYMERASE CHAIN REACTION IN MEDICAL DIAGNOSTIC FIELDS: A REVIEW. Brazilian Journal of Microbiology, [s.I.], n. 40, p.1-11. 2009. 